\title{
Narration and History in "Wadi Al- Safsafah " (Valley of Willow Tree) Novel by Ahmad Al Tarawneh
}

\author{
Khawla Shakhatreh \\ School of Management, Jadara University, Irbid, Jordan
}

\begin{abstract}
This paper discusses the narration and history in "Wadi Al-Safsafah" by Ahmad Al tarawneh, which focuses on Karak rebellion (El hayeh) in 1910, meanwhile it surpasses rather beyond to the present, and deals with the profound transformations taking place in Jordan society. The paper also discusses the narrative and historical dialect in the novel and the effort to naturalize it, then it shows the human aspects of the novel. The paper examines the narrative address : event, narrator, narration, and place. It concludes that the novel, with its narrative address, was able to express its idea and go beyond history to present its own understanding of an event that has ended, but its consequences are still present till now.
\end{abstract}

Keywords: Wadi al-Safsafah, Ahmad al-Tarawneh, Rebellion, Elhayeh, Turks, Narration and history, Karak

DOI: $10.7176 / \mathrm{HRL} / 52-04$

Publication date: December $31^{\text {st }} 2020$

\section{The study problem and Importance}

This paper investigates the narration and history in " Wadi Al safsafah" novel by Ahmad Tarawneh which was published in 2009 ( Al Tarawneh , 2012). The novel focuses on an important event in the modern history of Jordan, in Karak city in 1910, or as it was called locally "Hayyet Elkarak", while it was known as Karak incidents in the Arab press at that time, such as Almoqtabas, Al Bashir, as well as Ottoman newspapers such as Taneen , Alamdar, and Taqweem Waqae', which wrote about the rebellion according to the official records of the Ottoman state( record of the Share'iah court of Karak, 1912 ).

\section{Reasonning of the Study}

The novel " Wadi Al Safsafah " tackles the pre establishment period of the modern state of Jordan, a period which is almost absent from or ignored by the official history of Jordan. This period was absent from the school curricula though the students studied this period of the neighboring Arab countries in detail. Curricula in Jordan ignored what happened during this period, despite its importance, as the Syrian historian Munir al-Rayyis considerd it "among the glorious revolutions at the dawn of the Arab renaissance."(Rais, 1969, S23-34). Curricula focus on the next period, the Great Arab Revolution, which the Hashemite monarchy is based on its heritage, and derives its legitimacy from it.

Despite the importance of this novel topic, and the structure upon which it was based, it has not received an integrated academic study, where all published materials were only press reviews in electronic pages or some seminars .

\section{Study hypotheses:}

- How can the novel be naturalized?

- Did the author employ the oral and written historical material obtained, that included : songs , poetry and some folk tales?

- Was identity obsession present in the novel, and what is the extent of the human side presence?

- How appropriate is the narrative speech to the novel material?

\section{Research Methodology}

This study adopts two approaches:

1. A theoretical approach to understand the novel ground briefly.

2. An applied approach that focuses on narrative address.

\section{Naturalization of the Novel}

The novel under study was based on a historical event that had begun and ended in the early twentieth century. This event was reshaped within an integrated narrative address, based on historical documents, such as the records of Karak Share'ieah Court, the Ottoman records of the detained and executed persons, and the Ottoman leaders who suppressed this rebellion .

It also depended on the newspapers issued under the supervision of Ottoman State, in addition to the oral narrations that were passed down through generations. These narrations included many of the poems and songs 
about this event and its persons who planned and participated in.

Perhaps one of the most noticed examples of the songs that sticked to the mind, a song was repeated by the people before and during the rebellion, which says:

\section{Oh Sami Pasha we do not obey \\ We do not prepare our men for war \\ For the sake of Mashhas and other women \\ Fighting soldiers is our task}

This song is still the best proof of the importance of the event, which remained present in the memory, that framed the awareness of many people, expressed their identity, and became a part of the collective unconscious mind of Karak people, the South and entire Jordan .

The novel belongs to the past which we receive, as Ichir- Lakka Para indicates, "in the form of texts, memories , and texted remains, reports, published writings, archives, scripts, and memorial texts, etc." ( Manfred, 2015 p . 102).

We should take into account that the novelist was free of documents restrictions and literal forms. He did not commit to the historical events as occurred exactly, but he built the events of his novel on the historical material of Karak rebellion

Such raw material can be mined, structured, shaped, separated, and linked in the way the novelist considers" (Kathim, 2005, p . 16)

In other words, the novelist rearranged the order of events and shaped them according to a specific narrative plot of the novel. He is the one who puts an event before another, and makes this event a cause of another event with the resulting consequences, according to Kathim (Ricoeur, 2001, p. 8) and (Thales, 1952, p. 22).

This novel differs from the history books because the novelist does not tell everything, but he is keen to narrate his own insight of these events, and his understanding, away of the different conflicts at that time, so he activates isolation and selection law of events, and choses some of which that agreed with reading, analysis , and his own view.

This means that his choice for this event or that was not a coincidence, in order to build a convincing novel with credibility, and to fabricate situations.

"The novelist writes a novel using his knowledge, ideas, reflections, and imagination, just as the historian who writes history, since function is related to the core of process" ( Militc , 2005 , pp. 67, p. 200). It is a choice of relevance to the event.

Hitchon insinuates to something like this when she refers to the ability of story teller to stop talking, exclude whatever events and characters he wants from the past, and this is what historians used to do, otherwise, where was the role of women in these books? (Hitchon, 1993 , p . 98).

This exception has the function of the novel needed by the structure, in the sense that the novel abides by the historical facts, but at the same time it tries to narrate what the authority hides "( Miletc , p . 200), or what was ignored by official records on the event, and reconsiders people who participated in the rebellion, where the novel is concerned with people who made history under conditions that they did not create, as Marx mentioned (Ricoeur, 2001, p.11)

This different understanding of the event and its narration opens a space for debate and controversy over some issues that have arisen on the rebellion, such as: zero point, the beginning of the rebellion and the accompanying actions that might be contrary to the justice that leaders called for, or contrary to the pure revolutionary spirit, as a result of unforeseen circumstances. changed the deadline of rebellion launch (Al Tarawneh 2012, p148-149).

Perhaps it is an effort to understand, where this history may need to be held accountable (Manfred , 2015 , p . 117 ). History calls for the novel to fill the so-called its gaps - after its reproduction - when it does not find any historical sources that can help (Al- Hasnawi, 2017 , p. 41)

This controversy cannot be accommodated by history books that either ignore the event, or simply narrate it from the authority point of view, whether at the time of the incident occurrence or aftermath.

In any case, the narration of the historical event in the history books is stripped from any cultural plot ( Kathim, p11, 2005). That is why the narration, as Ricoeur views, brings together disparate elements of identity, and combines them in one unit in line with a coherent plot (Ricoeur, 1998 ,p250-267) .

The question that arises: why does the novelist seek help from history? We have to refer to the novel of Wadi Al Safsafah as it doesn't only narrate the historical event, but it bounces between the past and present. It goes through two parallel lines that start from the present and back to the past, then return to the present and back to the past, until the end of the novel.

Novelist gets help from the idea of a spiritual haven, such idea that took Lukash to a time of celebrating the original values that spirit goes to, and secures its full spontaneity (Darraj , $1999, \mathrm{p}$. 11 ). 
Such time has the nostalgia for innocence, where the novel re -narrates what authority obliterated, or what was ignored by other addresses that adopted authority view (Rashid, 2005, p . 128 ).

Since the novel generally presents the narration of eliminated and oppressed people who were ignored by the official view that overlooked their active role in these events, it provides them with a space to express their viewpoint about what happened, away from the authority and its partisans ( Miletic, 2005 , p . 200).

The novel challenges forgetfulness ( Rashid, 2005 , p. 154), brings to mind what happened, puts it in the foreground of concerns. It restores consideration to those simple people who have been absent in history, which is full of only leaders, medal holders . and officers; but the novelist revives life in these events, to stay everlastig in the memory of people.

The novel seeks to preserve the identity because it fear of loss and obliteration, and opens up to the ignored history . Huble says "With the goal to obliterate people, they begin to erase their memory, through disposing of their books, culture and history, meanwhile, others fake and impose new books ,culture and history. Then people slowly begin to forget their own identity and heritage while the world forget them more quickly ( Miletic, 2005 , p. 205$)$.

For this reason, the novelist works between two paths: historical fidelity and the requirements of novel art, so he begins to combine the characters in time-space framework (Alqadi, 1998 , p . 111-13). Therefore, the novelist accumulates all events then begins to screen them upon his own standards and selects the most appropriate for the novel sake, and excludes what he considers unsuitable.

\section{Novelist References and Sources}

Al Tarawneh exploited the history as his novel material. He read what had been written about the event in the newspapers issued during that period, and comprehended the oral narrations and folk songs that had been kept in the mind of people through generations. He also read the poems that mentioned the events as well as the official records of Ottoman State.

Readers of the novel can infer some documents that people kept, in which some events were recorded, or refer to the census processes that began with compulsory military drafting, especially since many of those who participated in the rebellion studied at Karak school, and some of them travelled to neighboring countries to pursue their education.

This partial notation ,if to speak, in addition to the oral memory kept the event in mind, were one of the approaches that the novelist recognized the main character of the novel, his father, who kept some old papers in a box to tell about what happened in the recent past, since the beginning of the rebellion until his death by hanging.

These papers indicate some situations and debates occurred, especially after the transfer of the detainees to Damascus for trial, then back to Karak with harsh humanitarian conditions of cold, hunger, death threats and unfair trials in addition to the difficult transportation of detainees handcuffed and jammed in vehicles.

Perhaps it is a narrative trick to delude the reader of the truth of narration, and perhaps to build bridges of trust between the reader and the narrative body, which is based on a document that was written and recorded.

The novel of "Wadi Alsafsafah" turned to the present, but this latter as shown by the novel, remained tied to the past in two different ways: it is a sense of injustice, ravage and fear of identity loss, which is still inherent to many of the present generation, if not roosting on the chests of many, despite the sacrifices of ancestors .

On the opposite side there is nostalgia to the past and awareness that united the south as a result of injustice and depriving, and the victory of the dignity and identity .

The novel goes into two parallel lines: from the present to the past, then back to the present, and so on until the end. This interplay between past and present reveals two different kinds of political awareness - in the past that united the people of the south from Madaba to Karak at the time of the rebellion, and a present awareness, in which the political forces and parties are fragmented where the society is divided due to the social and economic problems

\section{The Obsession of Identity and the Human Aspects}

The emphasis on identity in Jordan became an obsession among many Jordanians, especially after ignorance of Jordan history prior to establishment of the emirate in 1920, and led to many efforts to re write this history according to the rebellions of Jordanians for freedom, where the historical material became part of the novel material to avoid its loss or effacement

The novel of " Wadi Safsafah " departed itself from the sanctification of individuals or intolerance to place or tribe, and its characters are not arrogant nor mummified (Khadrawi, 2007 , S254- 255), but it is interested in the humanitarian situations embodied by the characters of the novel, which we express our admiration and sympathy. This human heritage is an important part of the identity defended by the novel.

The novel includes scenes of humanity far from intolerance or exaggeration : This is Khadra, wife of Hasan, torn by jealousy and driven by the fire of lust, for his frequent absence from home, but she didn't know that the 
reason of his absence was his fear for being distracted by the unknown situation which would happen to the people and country, he was concerned of her and others (Al - Tarawneh, 2012 S24-25) .

A person called (Abu Muhammad) is an example of nobility when he rewarded the loyal and hardworking shepherd, who was loyal to his work so he promised him to register some area for his land ownership in addition to breeding sheep, that allow him to work for his own. The reason of register delay was to let the shepherd avoid land ownership taxes that exceed his capacity, and the subsequent compulsory military drafting ( Tarawneh, 2012, p. $34-35$ ).

The scene of the mother providing assistance to others, and donates the Intifada(uprising) ( Al - Tarawneh, 2012, p . 47 ) and cares for people lives and their freedom, especially those who have been displaced from their village because of adherence to a norm called Jalwah (displacement), which imposed on people, whose some close indviduals commit crimes, to leave their homes, and live in an insecure environment, exposed to all kinds of injustice and abuse by their protectors ( Tarawneh, 2012, pp. 50-55 ).

These weak and fragile human models, with their simple desires indicating their goodness at times and the level of their thinking at other times, and an indication of their patriotism even if they do not have the ability to express, have become part of the narrative world, which gave the credibility to what is narrated.

The interest of the novel in the rebellion does not prevent it from halting at the moral and human side of some customs and traditions, and how these habits turned into a weapon that kills the present society

Since ancient times people agreed on a set of norms and laws, that are similar to the laws of social welfare, to protect people from tampering, and infringement. These laws constituted a system of protection for individuals as a result of the political gap at the time, and the shelter that reserve them from the dangers that threaten.

The paradox is that in the name of clinging to the past and tribal customs, society today practices injustice that proxime to crimes against humanity. If a person commits a murder, the criminal's family is punished, and everyone who is related to this family with blood ties, that sometimes reach 10 families, are punished by displacement from the village ,by the claim of protecting them from the revenge of the victim family.

With the absence of historical and social context, which imposed this tribal norm, and with the emergence of the state, such cling lose its real values; because the social context for this law was imposed by a previous historical and social context, so in the absence of these contexts, and the rule of law, such adherence lacks its true value for which this tribal custom was .It will be a new cause of injustice and suffering. This is what was seen closely by Dr. Ahmad, who was threatened to death by some families, for one of his far cousins committed murder ( Al - Tarawneh, 2012, p. 70 ).

One of the features that shaded the human aspect of the novel is the scene of Um Alghaith celebration, in which women bear a doll as a part of the social context which embraced the rebellion events. Such scene was accompanied by songs and rituals by women who pray for downpouring the rain, which was part of the customs, and part of the artistic and cognitive product based on the experience and practice.

What happened as a result of this scene of dispute between religious belief and the legacy of heritage , shaded the place and influenced the rebellion in both orientations: between those who support independence from the Ottoman Caliphate because they believed in their right to get freedom and justice, and those who adhered to the caliphate, since it meant religious affiliation according to their belief ( Al-Tarawneh, 2012 , pp. 101-105).

\section{Narrative Address in "Wadi Alsafsafah"}

We will discuss the most important constituents of the address that the novel was based on: : event, narrator, characters, and place .

\section{The Event}

The historical event of rebellion in 1910 constitutes the backbone of this novel, but it does not stop at, where it goes beyond to the decade of the nineties of the twentieth century; because the narrated historical event is still present in the mind of people, even it continues to affect their lives in one way or another.

The heavy legacy that Ahmad inherited shades him and his present, perhaps his personality was the best representation of the influence of past on present, so he kept trying for salvation.

The novel paves the way for the historical event with a dream that had been seen and narrated by unknown voice who says: "I saw my grandfather holding a small wood horse in his hand, and he rode on a long sword. I saw abundant hair on his back, and the sword entered his body, with red water dropping down but did not reach the floor. He was standing on a black clay statue, then the sword rose from his body and he called me loudly , my son: take this sword and slay this statue, let me rest". ( Al-Tarawneh, 2012, p. 17) .

That dream expressed each of them, their apprehension and fear of the future. The reaction was pessimism and fear of this dream, which predicted what would happen. Then the novel mentions the nightmare of Hasan who saw himself in a vast hallway, with a table carried by one stand, and a legged man was sitting on it , wearing a military uniform. 
The man ordered loudly a soldier to bring a whip. He stood on his one foot and approached Hassan, with angry features between his large eyebrows, then he planted his eyes in Hassan's face, whose feet seemed to be planted in the hallway floor, where the first whip fell on Hassan's bare feet, then his back." (Al-Tarawneh, 2012, p. 27).

This dream was a warning of the coming events, and foretold the role of Hassan role and what awaited him, especially since the dream prepared for the emergence of the character (Khadrawi, 2007 , p. 256) . All that happened in the novel later was an outsight of the coming events. The dream was anticipation of what would happen (Hamdani, 1991, p. 74 ).

The complaints increased against the practices of the Ottoman authority: tax collection despite famine, poor economic conditions, school closures, and compulsory military drafting to fight outside the state.

All these factors stimulated people to congest and reject these unjust practices, whether on the individual or collective level, through calling for a rebellion, then the factors that helped expedite the implementation, after the occurrence of new developments that did not cross the minds of those who planned the rebellion (Al-Tarawneh, 2012, pp. 146-147) .

The researcher traced the novel chronology of the preparation for Karak rebellion, without forgetting that any event is created by the characters, where it is a reflection of character (Rushdi, 1975, p . 30) .

The characters in this novel were divided into: high ranked personalities with a historical presence such as Sheikh Badr, Sami Al-Farouqi, and others, such as: Rajwa; and some of the characters imposed by the novelist world through the relationships that arose among those characters (Al- Qadi, 1998, p. 133), by virtue of planning the rebellion and meetings .

The historical novel is a narrative work that aims to reconstruct an era from the past, in an imaginative way, where historical figures overlap with fictional characters, that is we find a historical material, but it is presented in a creative and imaginative way" (Yaktin , 2005), p . 82 ).

Then the novel follows the developments that accompanied the return of Ahmad from Turkey - who was Hassan's grandson the martyr during the rebellion - and sheds light on the transformations that changed Karak community, not necessarily for the better, and which indicate changes in the Jordanian society in general.

Ironically, Ahmad studied medicine in Turkey, which his family and ancestors revolted against it, where each side was entrenched to fight the other party for freedom and justice, but he returned this time to face: unemployment, poverty, and a person from his village, waiting his return to kill him under the name of revenge.

\section{Narrator and Narration}

The influence of history was not limited to the characters alone, but rather went beyond, to how the event and narration were narrated in the novel. That is why the novel starts from the present to past in two parallel tracks: the present to the past, then returns to the present where the novel ends, with focus on Ahmad, a grandson of the martyr Hassan who was sentenced to death during the rebellion.

Some events of the novel are presented in the form of 3rd person pronoun as external narrator ( Bornov, and Aoialah, 1991 , p . 79-83 ). "Hasan arrived in his home as a body, but his spirit is still flying over the arabs, watching what is going on, and whispering to the ghosts of friends, looking for opportunity for salvation .." (Tarawneh 2012, p . 71).

Other events are narrated by a 1st person pronoun as the internal narrator ( Bornov, and Aoialah , 1991 , p . 79-83.) and Lhamdani , 1991, p . 49).

The shift in the narrative from external to internal narrator was required by the sequence and development of events. Dr. Ahmad found the box of his grandfather, which contained some yellow papers in which Hasan wrote what had happened.

Grandmother tells Ahmad what Hasan had said to his friend Abu Mohammad prior to his execution, and how the latter took the papers and gave it to Hasan's son after years. Hasan told Abu Mohammad that "give these papers, I wrote in prison, and some items, to little Hasan and take care of him and his mother Khadra "(Tarawneh 2012, p . 224).

The novel presented the will of Hassan as a narrator and participants in the events , " Oh, my uncle, I saw death today so I wished I had died, our horses were tired of hit and run, we jumped off them and unwrapped their saddles to graze, since we thought the battle was over, but we did not know that there was an evil enemy leader" ( Al-Tarawneh, 2012 , p. 187).

The access to his grandfather box , which included some papers and collections dating back to the time of the rebellion, required Ahmad to read these papers, in order to narrate events as recorded, and from his grandfather's point of view as an active individual in the rebellion since the beginnings of preparation, and one of the fiercest enthusiasts for it, and indeed was one of the first to incite the rebellion and plan it.

The alternation in the narration of one event with the 3 rd person pronoun once and the 1 st person pronoun in another provides opportunity to indicate reference to the relationship between the novel and the reader in what is known as the point of view (Prince, 2003, pp. 153-154) .

Narrator from the outside as the 3rd person, and the narrator from the inside as the 1st person pronoun, 
shows that the narrator tells about another character within the novel body, such as Hamidah, or diaries such as Hassan's diaries that he made sure to reach his son and grandson after him.

The search for answers to urgent questions led Dr. Ahmad to find this box, after return from Turkey, so he could recognize many of the rebellion details, which were not known but only by the participants who lived difficult conditions, and suffered the bitterness of exile and agony in the journey of death from Karak to Damascus, and from Damascus back to Karak.

There were mock trials, and the death penalty for a group of participants, by throwing them from the top of the castle, or stabbing with spears (Al-Tarawneh, 2012, pp. 216,218) .

\section{The character}

In "Wadi AlSafsafah " novel a large group of characters participated in the event due to its importance but we can stop by a group of characters who occupied an important place.

That participation varied from character to another, where some of them had a historic presence like Badir(Qadir Almajali) and Sami Alfarouqi (Ottoman military leader),for instance, and between a character that may seem imagined but has a counterpart in reality .

Karak rebellion included aware personalities, who had a role in inciting, organizing, and demanding rights, calling for freedom, and establishing a state with its own laws.

They included Hasan's character, which was presented by other personalities, such as : his mother ,his friend Abu Muhammad, his wife Khadra, Sheikh Badir, in addition to his debates with people before the declaration of the rebellion, during the planning, and the dream.

This type of narration aimed to ensure preparation of the receiver to its appearance, and predict what would happen in the future, so the receiver awaited what would happen to Hassan and his end, whether it was Hasan the dreamer or Abu Mohammed, who ensured raising Hasan's son, with reference to the statement by the narrator ,from the description of his character, which was identified and colored in proportion to the structure of " Wadi Safsafa " .

They have a role in building the event and its development, and have ties with the network relationships with characters of the novel, where the narrator was a complex character, that was not presented once, since it spreads over the space of the novel, from its beginning until the last page (Tarawneh, 2012, pp. 156 , 208-209, $217,221,223)$.

Among the characters that did not have a wide space within the novel, but had an active presence in the events, and an influential role on other characters with their rich debates that clarified their point of view , and at the same time represented the viewpoint of those around or who lived the same circumstances, so it remained stuck in the mind .

An example of these characters were Khadra and Abu Mohammed as they have every attributes of human presence in the community in which they lived, but exceeded human feeling when she wanted to donate its goat to the uprising.

The presentation of each character in the novel varied according to their role, so the novel sticked to presenting the character of Sheikh Badr - Qadir al - Majali - with the information known about him that remained present in the minds of people.

There were struggle, human and emotional aspects, as well as his denial of membership in the council despite his right to get it, and about his relationship with his wife, who he remained loyal to , so he did not marry despite not having children (Al-Tarawneh, 2012, pp. 38-40), while despite his preoccupation with serious matters, the novel focused on his emotional relationship .

Hasan personality has remained fresh in the minds, indicating his desire for freedom, through awareness and knowledge, since he was the intellect who was reading newspapers, and following up what was published by the press abroad about the weakness of the the Ottoman state, which was on contrary to what it had claimed in the arab regions, and in the same time its desire to draft the largest number of arab men to fight in far fields .

Such awareness was that prompted Hasan to write down his diaries, during the journey of death, in order to remain a witness of what happened, a document that the novel was interested in which formed a corner, where Hasan was the best example of knight ( Tarawneh, 2012), who held the chivalry principles and values through his bedouin origin, which respected and glorified these values.

Hasan objected some retaliatory actions, by some rebels, that contradicted principles that they were calling for , and objected compelling women to serve the Ottomans ( Tarawneh, $2012, \mathrm{p}$. 146), and refused all kinds of oppression with nobility and chivalry, as if the novel wanted this to embody the character of the knight or chivalry inside him to represent the last of the knights, away from political consideration, where he faced death

It is true that he was not superstitious, but rather presented his character that indicated humanity, through moments of weakness ( Tarawneh, 2012 , p. 195), fear, hunger, anxiety, cold, and facing death.

He witnessed the execution of many colleagues especially that one who tried to take the priority place before his uncle so that his mother would not mourn him, which was a true story ( Tarawneh, 2012 , p. 222).

Hasan and Qadir were two sides of the same coin, each one wanted to achieve justice and freedom, but with 
different approaches. Abu Muhammad and the mother, represented the opinion of wisdom, experience, patience, agony, and altruism.

The traitor who reported the names of participants before and during the rebellion and was rewarded by the Ottoman, did not differ from that who exploited people's misfortunes when someone faced revenge, or exploited people's need and practiced brokerage in the present .and exploits any opportunity to make profit away from morals and principles.

\section{The place}

The question is: How did Karak appear in this novel as the place of rebellion? Did history overwhelm the place?

The novel did not present Karak as a still picture for a specific period, nor it was just a background for the events, but the historical event overshadowed the description of the place, defined its features, and remained in control of the novel.

The reader can stop at four places which were capable to show Karak through history, while they were inextricably linked:

1. The box " his hands touch the box, like a dead body, the smell of the place is heavy, these yellow papers are burried in bundles of cloth like coffins. laying in a wooden hole that has not left its place for a long time, foul dust, and the smell of rotten gunpowder, bursts of human blood blackened by oblivion, ghosts of spirits escaping " ( Al-Tarawneh, 2012, p. 14).

This box tells the forgotten and deprived history, on yellow papers stained with blood that talked about what happened for detainees, and described their journey to death - from Karak to Damascus and back to Karak, but they left behind five detainees - executed in Damascus, and in Karak after the mock trial, verdict of death was issued, on the participants in rebellion, by hanging or throwing from the top of the castle .

He has contacted the ghosts of the past, no wonder that his mother suffered from insomnia in the night when Ahmad opened the box, as if the lives of the rebellion victims were hovering around the place: the house, street, city, Jordan.

The death by throwing from top of the castle means passing by the willow tree that witnessed the moment the convicted men were falling by so the reader travels to the second place

2. Al Safsafa ( Willow tree) that stretched high in the sky as the castle it guards. " it grew long before the Ottoman Empire" ( Al - Tarawneh, 2012 , p . 218). Thus, its people recognize it as a tight and deep rooted tree , which extends to hundreds of years, and stretches high and wide to cover Karak and the nation. It witnessed the agonies of detainees and the moments of their execution, but remained firm and lofty .

3. The third place :. The Castle ( Al - Tarawneh, 2012, S178-183), which was mere a garrison hidden in the basements of the governer, and remembered only when they collect taxes or draft soldiers, but - as seen by the angel Ahmad, it was present strongly in various contexts on his tongue:

He tells the history of the city to his Turkish wife while looking at the deep valley surrounding the castle , which saw the death of both sons of Ibraheem Aldmour, who sacrificed them in order to preserve an outsider fugitive to Karak, Sheikh Qassem Al - Ahmad, who escaped from Nablus, where Aldmour refused to handover him to Ibrahim Pasha .

Ahmad then conjures the gloss of Salah al-Din al-Ayoubi sword as if he saw him with his naked eyes when he placed it somewhere in the castle to perform ablution, then Ahmad returns to the ancient history of the city where Mesha'a was dragging one of the traitors who cooperated with the Hebrews.

It was a tiny scene, but it confirms to the grandson narrator and us that the traitors reproduce, where some of them revealed the weaknesses of the rebellion, and were the cause of the increase in the number of victims.

4. The fourth place was the fig tree ( Tarawneh, 2012, p30-31) which Hassan brought from Damascus , and planted near the well in the courtyard of his house, then became the preferred place for the wife, the son and grandson to sit under it.

It is not just a fig tree that people rest under its shadow, and eat its fruit, but has turned into the intimate place where the wife, son and grandson meet later, the place that cures the wounds of the past, and removes the ghost of sadness and mourning for everyone who perished as a martyr or a prisoner.

At this place they will remember the year of rebellion (Elhayyeh) and what happened in the past, while not distracting themselves from the concerns of the present, with all its poverty, unemployment, revenge, etc., nor about Palestine or Iraq.

\section{Conclusion}

1. Wadi Alsafsafah is a novel that combines the past, that is based on the document and oral narrations, and the present, that is based on a part of the past and an imagined one.

2. The novel depends on the rebellion event (Elhayeh), but it goes beyond this event to build an integrated narrative text of event, characters, time and place.

3. In creating the characters, the novel moved away from claiming heroism or mastery, but well structured characters that suit the novel structure without fabrication nor coincidence. 
4. The place appeared in different forms and indicated new connotations, far from the decoration or the place that witnessed the event.

5. The span between the past and the present has relationship with the awareness that governs the novel's characters.

6. Since that time when Hasan hid the papers in the box, it collaborated with the dream, debates, songs, narrations and speech with 1 st person pronoun once and 3rd person pronoun in another incidence, to create a novel world redundant between past and present .

Sources and References: (Titles in Arabic are translated)

Al-Hasnawi , Abdul Rahim ( 2017 ). Historical Narration and Novel narration: Search in levels of address . Journal of Capital : Kerala, Vol (9).

Alqadi, Muhammad ( 1998 ). Novel and History : Two Approaches in Writing History through Novel, Jeddah: Alamat Magazine, Literary Cultural Club, Issue ( 28 ), Volume ( 7 ).

Al Rayyes, Mounir ( 1969 ). The Golden Book of the Arab Rebellions, Beirut : Dar Al Talee'a

Altarawneh , Ahmad ( 2012 ). Wadi Alsafsafah, Ministry of Culture : Jordan Family Library .

Burnouf, Roland, and O'eli , Real ( 1991 )The World of Novel . Translator: Nihad Altkrli, Baghdad : Public cultural Affairs .

Daraj , Faisal ( 1999 ). The theory of the Novel and the Historical Novel, Beirut, Casablanca Casablanca :Arab Cultural Center .

Hutchon , Linda ( 1993 ). Novel of Historical Narration, entertainment by past , translation : Shukri Mujahid, Fosoul Journal : Public Egyptian Commission, Cairo, Vol . (12), Issue (2) .

Khadrawi , Idris ( 2007 ). Imagined and History, and the Paradox of Identity in Prince Novel by Wassini AlAraj. Fusoul Journal,Egyptian Public Commission for book, issue 71

Kharouf , Samah ( 2015 ). The Historical imagined 1 in the novel " Prince " by Wasini Alaraj, Journal of Qadisiyah, Volume 15 , Issue ( 2 ).

Kathim , Nader ( 2005 ). The novel and re- plot of history, Cultural Bahrain Journal, Volume 12 , Issue ( 41 ) .

Lahhamdani , Hameed ( 1991 ). The structure of Narrative text, from the perspective of literary criticism , Beirut, Casablanca : Arab Cultural Center

Manfred, Ban ( 2010 ). Aesthetics beyond storytelling: studies on the post modernity novel, translation : Amani Abu Rahma, Syria: Dar Ninawa

Militc , Katarina ( 2005 ). History changes or Book of Laughter and Forgetting , Translation: Amal Alsabban, Fosoul Journal : the Egyptian General Authority of the book, issue 67

Naseer, Mahdi ( 2013 ). Narration of the forgotten history , Al- Dustour newspaper ,28/6/2013

Prince, Gerald ( 2003 ). Narrative Dictionary . translated by : Sayyid Imam, Cairo : Dar Merit for Publishing

Rashid , Ameena ( 2005 ). Narrative history and historical Literary text, Fosoul Journal : Egyptian Public Commission for Book, Cairo, the issue 67

Ricoeur, Paul ( 1998 ). Existence, time and narration , translated by : Said Al - Ghanimi, Beirut : Arab Cultural Center Ricoeur, Paul ( 2001 ). From the text to act, research of interpretation, translated by : Mohamed Berrada and Hassan Bourkia, Cairo: Ain for Social and Human Studies and Research .

Rushdie , Rashad ( 1975 ). The art of Short story ,2nd ed,Dar Oudah, Lebanon

Sharia Court Record of Karak (1912)

Thales, Aristotle ( 1952 ). The art of poetry, Translated by : Abdul Rahman Badawi, Beirut: Dar Althaqafah

Yaqteen , Saeed ( 2005 ). Historical novel and the issues of literary genre, Nazwa Journal : Oman Establishment for Press and News, issue 41. 